\title{
The impact of preoperative identification of the Adamkiewicz artery on descending and thoracoabdominal aortic repair
}

\author{
Hiroshi Tanaka, MD, PhD, ${ }^{\text {a }}$ Hitoshi Ogino, $\mathrm{MD}, \mathrm{PhD},{ }^{\mathrm{a}, \mathrm{b}}$ Kenji Minatoya, $\mathrm{MD}, \mathrm{PhD},{ }^{\mathrm{a}}$ \\ Yoshiro Matsui, MD, PhD, ${ }^{\mathrm{c}}$ Tetsuya Higami, MD, PhD, ${ }^{\mathrm{d}}$ Hitoshi Okabayashi, MD, PhD, \\ Yoshikatsu Saiki, MD, PhD, ${ }^{\mathrm{f}}$ Shigeyuki Aomi, MD, PhD, ${ }^{\mathrm{g}}$ Norihiko Shiiya, MD, $\mathrm{PhD},{ }^{\text {, }}$ \\ Yoshiki Sawa, MD, PhD, ${ }^{\mathrm{i}}$ Yutaka Okita, MD, PhD, ${ }^{\mathrm{j}}$ Taijiro Sueda, MD, PhD,${ }^{\mathrm{k}}$ Hidetoshi Akashi, MD, PhD, ${ }^{1}$ \\ Yukio Kuniyoshi, $\mathrm{MD}, \mathrm{PhD},{ }^{\mathrm{m}}$ and Takahiro Katsumata, $\mathrm{MD}, \mathrm{PhD},{ }^{\mathrm{n}}$ the Japanese Study of Spinal Cord \\ Protection in Descending and Thoracoabdominal Aortic Repair investigators
}

\begin{abstract}
Objective: To investigate the impact of preoperative identification of the Adamkiewicz artery (AKA) on prevention of spinal cord injury (SCI) through the multicenter Japanese Study of Spinal Cord Protection in Descending and Thoracoabdominal Aortic Repair (JASPAR) registry.

Methods: Between January 2000 and October 2011, 2435 descending/thoracoabdominal aortic repairs were performed, including 1998 elective repairs and 437 urgent repairs, in 14 major centers in Japan. The mean patient age was $67 \pm 13$ years, and $74.2 \%$ were males. There were 1471 open repairs (ORs), including 748 descending and 137 thoracoabdominal extent [Ex] I, 136 Ex II, 194 Ex III, $115 \mathrm{Ex} \mathrm{IV}$, and $138 \mathrm{Ex} \mathrm{V}$, and 964 endovascular repairs (EVRs). Of the 2435 patients, $1252(51 \%)$ underwent preoperative magnetic resonance or computed tomography angiography to identify the AKA.
\end{abstract}

Results: The AKA was identified in 1096 of the 1252 patients who underwent preoperative imaging $(87.6 \%)$. Hospital mortality was $9.2 \%(\mathrm{n}=136)$ in those who underwent OR and 6.4\% $(n=62)$ in those who underwent EVR. The incidence of SCI was $7.3 \%$ in the OR group (descending, $4.2 \%$; Ex I, 9.4\%; Ex II, $14.0 \%$; Ex III, $14.4 \%$; Ex IV, $4.2 \%$; Ex V, $7.2 \%$ ) and $2.9 \%$ in the EVR group. The risk factors for SCI in ORs were advanced age, extended repair, emergency, and occluded bilateral hypogastric arteries. In ORs of the aortic segment involving the AKA, having no AKA reconstruction was a significant risk factor for SCI (odds ratio, $2.79,95 \%$ confidence interval, $1.14-6.79 ; P=.024)$.

Conclusions: In descending/thoracoabdominal aortic repairs, preoperative AKA identification with its adequate reconstruction or preservation, especially, in ORs of aortic pathologies involving the AKA, would be a useful adjunct for more secure spinal cord protection. (J Thorac Cardiovasc Surg 2016;151:122-8)

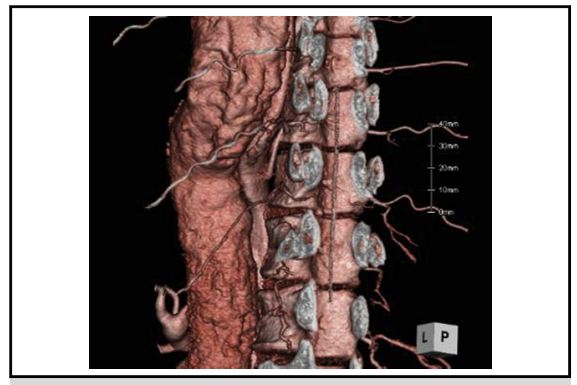

The Adamkiewicz artery, which arises from the intercostal artery in the aneurysm, is depicted.

\section{Central Message}

Identification of the Adamkiewicz artery would be an adjunct for spinal cord safety in descending/thoracoabdominal aortic repairs.

\section{Perspective}

For spinal cord safety, preoperative anatomic comprehension of spinal cord circulation would be beneficial as an adjunct in conjunction with appropriate subsequent strategies and surgical techniques, including other protective supports. Subsequently, the outcomes of aortic repairs would be improved, with lower mortality and morbidity rates.

See Editorial Commentary page 129.
From the a Department of Cardiovascular Surgery, National Cerebral and Cardiovascular Research Center, Suita, Osaka, Japan; ${ }^{\mathrm{b}}$ Department of Cardiovascular Surgery, Tokyo Medical University, Tokyo, Japan; ${ }^{c}$ Department of Cardiovascular Surgery, Hokkaido University, Sapporo, Japan; ${ }^{d}$ Second Department of Surgery, Sapporo Medical University, Sapporo, Japan; ${ }^{\mathrm{e}}$ Department of Cardiovascular Surgery, Iwate Medical University, Morioka, Japan; ${ }^{\mathrm{f}}$ Department of Cardiovascular Surgery, Tohoku University, Sendai, Japan; ${ }^{\mathrm{g}}$ Department of Cardiovascular Surgery, Tokyo

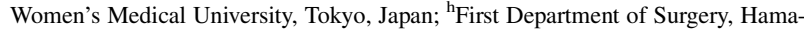
matsu Medical University, Hamamatsu, Japan; ${ }^{\mathrm{i}}$ Department of Cardiovascular Surgery, Osaka University, Osaka, Japan; ${ }^{j}$ Department of Cardiovascular Surgery, Kobe University, Kobe, Japan; ${ }^{\mathrm{k}}$ First Department of Surgery, Hiroshima University, Hiroshima, Japan; 'Department of Surgery, Kurume University, Kurume, Japan; ${ }^{\mathrm{m}}$ Second Department of Surgery, Ryukyu University, Nishihara, Japan; and
${ }^{\mathrm{n}}$ Department of Thoracic and Cardiovascular Surgery, Osaka Medical University, Osaka, Japan

This multicenter study was supported by research funding from the Ministry of Health, Labor, and Welfare of Japan (grant\# H20-Cardiology-017).

Received for publication March 18, 2015; revisions received July 22, 2015; accepted for publication July 24, 2015; available ahead of print Sept 3, 2015.

Address for reprints: Hitoshi Ogino, MD, PhD, Department of Cardiovascular Surgery, Tokyo Medical University, 6-7-1 Nishishinjuku, Shinjuku-ku, Tokyo 160-0023, Japan (E-mail: hogino@tokyo-med.ac.jp). $0022-5223 / \$ 36.00$

Copyright (C) 2016 by The American Association for Thoracic Surgery http://dx.doi.org/10.1016/j.jtcvs.2015.07.079 


$$
\begin{aligned}
& \text { Abbreviations and Acronyms } \\
& \begin{aligned}
\mathrm{AKA}= & \text { Adamkiewicz artery } \\
\mathrm{CPB} & =\text { Cardiopulmonary bypass } \\
\mathrm{CT} & =\text { Computed tomography } \\
\mathrm{EVR} & =\text { Endovascular repair } \\
\mathrm{Ex} & =\text { Thoracoabdominal extent } \\
\mathrm{JASPAR}= & \text { Japanese Study of Spinal Cord } \\
& \text { Protection in Descending and } \\
& \text { Thoracoabdominal Aortic Repair } \\
\mathrm{OR} \quad= & \text { Open repair } \\
\mathrm{SCI} & \text { Spinal cord injury }
\end{aligned}
\end{aligned}
$$

Spinal cord injury (SCI) remains one of the most devastating complications in descending and thoracoabdominal aortic repairs. For spinal cord protection, various adjuncts, such as distal aortic perfusion, hypothermia, preservation or reattachment of the responsible intercostal arteries, cerebrospinal fluid drainage, and pharmacologic agents, have evolved. ${ }^{1}$ Although the causes of SCI in aortic surgeries are considered multifactorial, further comprehension of the spinal cord circulation can provide the fundamentals of SCI prevention. In these settings, the anatomic details of spinal cord vasculature, first described by Adamkiewicz, ${ }^{2}$ have been focused on in aortic surgeries, and the development of its imaging modalities enabled identification of the location of the arteria radicularis anterior magna (Adamkiewicz artery [AKA]) preoperatively.

Although the anatomic and physiological importance of the AKA for spinal cord circulation is overwhelming, there is a dearth of literature supporting the importance of the AKA in aortic surgery. Some reports advocate that routine surgical implantation of the intercostal arteries including the AKA is not indicated with acceptably low rates of SCI, because the collateral network protects the spinal cord more than the segmental intercostal arteries do. ${ }^{3}$ With contemporary approaches to optimize spinal cord circulation during aortic repairs based on these theories, the incidence of SCI has dropped to $3 \%-8 \%{ }^{4,5}$; however, compromising such a collateral network, for example due to atherosclerosis in the elderly, might result in SCI. Surgeons still must struggle with uncertainties when aiming for spinal cord protection. In Japan, preoperative AKA identification and reference to these findings during aortic repairs is a widespread practice. ${ }^{6,7}$ Consequently, we conducted a retrospective investigation of the impact of preoperative identification of the AKA on reducing the incidence of SCI in open aortic repairs (ORs) and endovascular repairs (EVRs) for descending and thoracoabdominal aortic pathologies through the multicenter Japanese Study of Spinal Cord Protection in Descending and Thoracoabdominal Aortic Repair (JASPAR).

\section{PATIENTS AND METHODS Definitions}

In ORs, descending or thoracoabdominal aortic replacement was defined as the prosthetic graft replacement of the aorta below the left subclavian artery. The extent of thoracoabdominal aortic replacement was classified according to the scheme of Safi and coworkers, ${ }^{8}$ which was modified from Crawford's original classification scheme. Transverse arch and proximal descending aortic replacement through a median sternotomy, hybrid arch repair with stent grafts, and proximal descending aortic repair with a frozen elephant trunk were excluded. In EVRs, hybrid procedures with preceding bypasses of the arch vessels or visceral arteries were included.

\section{Data Collection}

The clinical data were collected from 14 major cardiovascular surgical centers in Japan through the JASPAR registry, which was established in 2010 to demonstrate the efficacy of preoperative AKA identification for spinal cord protection in descending and thoracoabdominal aortic repairs. Online data submission began in April 2010. Surgeons at the referral centers electronically submitted their data for patients who had undergone descending and thoracoabdominal aortic repairs since January 2000 into the database of this registry, which is located at the National Cerebral and Cardiovascular Research Center in Osaka, Japan. The present study was an analysis of the retrospective and prospective database and variables, including patient demographic data, preoperative imaging, operative procedure, and postoperative morbidity and mortality. Hospital mortality was defined as mortality occurring within 30 days after surgery or later if the patient remained hospitalized. The database was locked for this study on October 10, 2011. The Institutional Review Board of each participating surgical center approved this study; informed consent was waived for the patients who had undergone the treatment before the registry was initiated and obtained for those who underwent treatment after its establishment.

\section{Preoperative Identification of the AKA}

Twelve of the 14 participating institutions had started preoperative examination for AKA identification between 2000 and 2010. At some institutions, the preoperative examination was routine for all patients whenever possible, even in the emergency settings, whereas in others it was not routine for various reasons, such as surgeon preference, insufficient time before urgent surgery, patient refusal, and so on. Data included records of patients with or without preoperative examination, imaging modalities with or without AKA identification, and location of the AKA.

\section{Operative Procedure}

For the ORs, the surgical protocols were applied for this study were not standardized; however, the main surgical principles were similar in all institutions and included both mild hypothermia on partial cardiopulmonary bypass $(\mathrm{CPB})$ and distal aortic perfusion and deep hypothermia with $\mathrm{CPB}$ for some patients, according to the protocol of each center. Data recorded included the extent of surgery, temperature management, and the location of reattachment of the intercostal arteries. In the EVR group, the proximal and distal landing zones and the bypass methods for debranching of major aortic branches were recorded.

\section{Study Design and Data Analysis}

To investigate the efficacy of preoperative AKA identification, the results of aortic treatment were presented separately for OR and EVR. The primary endpoint is to clarify whether preoperative AKA identification 
TABLE 1. Demographic data and associated conditions

\begin{tabular}{|c|c|c|c|}
\hline Variable & $\begin{array}{c}\text { OR } \\
(n=1471)\end{array}$ & $\begin{array}{c}\text { EVR } \\
(n=964)\end{array}$ & $\begin{array}{c}P \\
\text { value }\end{array}$ \\
\hline Age, $y$, mean \pm SD & $64 \pm 13$ & $71 \pm 11$ & $<.001$ \\
\hline Male sex, $\mathrm{n}(\%)$ & $1069(72.7)$ & $738(76.6)$ & $<.001$ \\
\hline Hypertension, $\mathrm{n}(\%)$ & $1213(82.5)$ & $797(82.7)$ & .891 \\
\hline Hyperlipidemia, n (\%) & $370(25.2)$ & $236(24.5)$ & .707 \\
\hline Diabetes, $\mathrm{n}(\%)$ & $157(10.7)$ & $129(13.4)$ & .042 \\
\hline Smoking, n (\%) & $827(56.2)$ & $531(55.1)$ & .580 \\
\hline Coronary artery disease, $\mathrm{n}(\%)$ & $254(17.3)$ & 168 & .918 \\
\hline Renal failure, n (\%) & $202(13.7)$ & 143 & .445 \\
\hline Dialysis, n (\%) & $51(3.4)$ & $36(3.7)$ & .728 \\
\hline Cerebrovascular disease, $\mathrm{n}(\%)$ & $189(12.8)$ & $153(15.9)$ & .035 \\
\hline Chronic lung disease, n (\%) & $253(17.2)$ & $215(22.3)$ & .001 \\
\hline Liver disease, $\mathrm{n}(\%)$ & $8(0.5)$ & $19(2.0)$ & .001 \\
\hline \multicolumn{4}{|l|}{ Aortic pathology, n (\%) } \\
\hline Dissecting & $539(36.7)$ & $240(24.9)$ & $<.001$ \\
\hline Nondissecting & $837(56.9)$ & $636(66.0)$ & $<.001$ \\
\hline Infected & $79(3.2)$ & $28(2.9)$ & .003 \\
\hline Emergency repairs, n (\%) & $253(16.8)$ & 190 & .116 \\
\hline Preoperative AKA identification, $\mathrm{n}(\%)$ & $748(50.8)$ & $374(38.8)$ & $<.001$ \\
\hline Patent bilateral hypogastric arteries, $\mathrm{n}(\%)$ & 1258 & $894(86.0)$ & $<.001$ \\
\hline
\end{tabular}

would contribute to reduction of SCI in OR and EVR for descending/thoracoabdominal aortic pathologies. The secondary endpoints are to demonstrate risk factors for SCI in both repairs and to investigate for which groups of patients preoperative AKA identification would have a significant impact on spinal cord safety. Categorical variables and continuous variables are presented as frequency, and continuous variables are presented as mean \pm standard deviation. Cox multivariate analysis was used for the analyzing the effectiveness of preoperative AKA identification for spinal cord protection, and statistical analysis was performed using SPSS software (SPSS, Chicago, Ill).

\section{RESULTS}

The data of 2435 patients operated on between 2000 and 2011 for descending/thoracoabdominal aortic disease were included in the JASPAR registry. Of these 2435 patients, $1471(60.4 \%)$ underwent OR and 964 underwent EVR. Demographic data and associated conditions are summarized in Table 1. The patients undergoing EVR were older than the patients undergoing OR. The incidence of preoperative AKA identification was higher in the OR group. Slightly more than one-half $(51.4 \%$; $n=1252$ ) of the enrolled patients underwent preoperative examination for the AKA, and the AKA was identified in 1096 of these patients $(87.5 \%)$. The laterality and distribution of AKA locations are shown in Figure 1. Even in emergency surgeries, the AKA was identified preoperatively in 34 of 253 patients $(13 \%)$ in the OR group and in 16 of 190 patients $(8.4 \%)$ in the EVR group, either because the AKA could be visualized simultaneously on the preoperative enhanced computed tomography (CT)

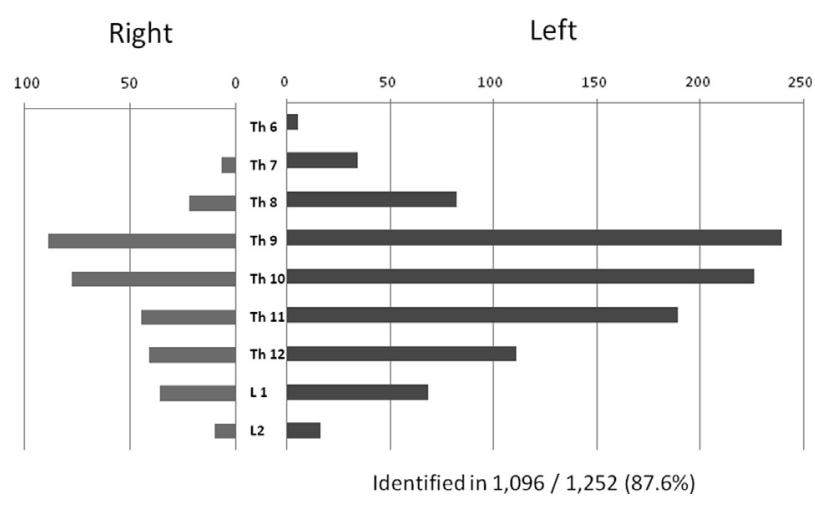

FIGURE 1. Distribution of the location of the identified AKA.

scans or because there was sufficient time for an examination before urgent surgery. These data were subsequently included in our analysis.

\section{Hospital Mortality}

The incidence of hospital mortality for each degree of OR is shown in Table 2. In the OR group, overall mortality was $9.2 \%$ (136 of 1471), including $4.3 \%$ in descending, $10 \%$ in thoracoabdominal Ex I, $10.0 \%$ in Ex II, $13.2 \%$ in Ex III, $7.8 \%$ in Ex IV, and $9.3 \%$ in Ex V. In the EVR group, mortality was $6.4 \%$ (62 of 964). Risk factors for hospital mortality were advanced age ( $>65$ years), preoperative renal failure, and emergency surgery (Table 3 ).

\section{SCI}

The overall incidence of SCI in the OR group was $7.2 \%$ (descending, 4.3\%; thoracoabdominal Ex I, 9.5\%; Ex II, $14.0 \%$; Ex III, 14.4\%; Ex IV, 4.3\%; Ex V, 7.2\%). The incidence of complete SCI was $3.8 \%$, and that of incomplete SCI was $3.4 \%$. Univariate analyses of the risk factors for SCI are shown in Table 4. The risk factors for SCI in the subsequent multivariate analysis were advanced age $(>65$ years), extended repair (Ex I/II), emergency repair, and occlusion of the bilateral hypogastric arteries in the OR group

TABLE 2. Rates of hospital mortality and SCI in OR

\begin{tabular}{|c|c|c|c|c|c|}
\hline \multirow[b]{2}{*}{ Aortic pathology } & \multirow[b]{2}{*}{ n $(\%)$} & \multirow{2}{*}{$\begin{array}{c}\text { Mortality, } \\
\%\end{array}$} & \multicolumn{3}{|c|}{ SCI, \% } \\
\hline & & & Complete & Incomplete & Total \\
\hline Descending & $748(50.8)$ & 4.3 & 1.1 & 3.2 & 4.3 \\
\hline \multicolumn{6}{|l|}{ Thoracoabdominal } \\
\hline Extent I & $137(9.3)$ & 10.0 & 3.7 & 5.8 & 9.5 \\
\hline II & $136(9.2)$ & 10.0 & 8.1 & 5.9 & 14.0 \\
\hline III & $194(13.1)$ & 13.2 & 10.3 & 4.1 & 14.4 \\
\hline IV & $115(7.8)$ & 10.5 & 1.7 & 2.6 & 4.3 \\
\hline V & $138(9.3)$ & 5.7 & 3.6 & 3.6 & 7.2 \\
\hline Total & 1471 & 9.2 & 3.8 & 3.4 & 7.2 \\
\hline
\end{tabular}

SCI, Spinal cord injury. 
TABLE 3. Multivariate analysis of risk factors for hospital mortality

\begin{tabular}{lccr}
\hline \multicolumn{1}{c}{ Variable } & Odds ratio & $\mathbf{9 5} \%$ CI & $\boldsymbol{P}$ value \\
\hline Male sex & 1.08 & $0.79-1.48$ & .611 \\
Age $>65$ y & 1.92 & $1.37-2.70$ & $<.001$ \\
Chronic lung disease & 1.37 & $0.97-1.93$ & .072 \\
Renal failure & 2.81 & $2.10-3.75$ & $<.001$ \\
Extended repair (Ex I/II) & 1.34 & $0.97-1.87$ & .074 \\
Emergency & 3.51 & $2.70-4.55$ & $<.001$ \\
\hline
\end{tabular}

Significant $P$ values (<.05) are in bold type. $C I$, Confidence interval.

and renal failure and emergency repair in the EVR group (Table 5). Overall, preoperative AKA identification had no significant impact on the prevention of SCI; however, in the subgroup of patients with OR for aortic segments involving the identified AKA (Table 6) in the red box in Figure 2 (patient characteristics are shown in Table 6), advanced age ( $>65$ years) and closure of the identified AKA without reconstruction were significant risk factors for SCI (Table 7).

In the EVR group, the overall incidence of SCI was only $2.9 \%$. The AKA was identified preoperatively in 343 patients (36\%), of whom $119(35 \%)$ had the AKA covered by an endovascular prosthesis. There was no significant difference in the incidence of SCI between patients with the AKA covered and those without the AKA covered $(3.3 \%$ [ 4 of 123 ] vs $2.9 \%$ [6 of 210]; $P=.74)$.

\section{Other Complications}

Other postoperative complications are listed in Table 8. For this study, these complications are defined as follows: prolonged ventilation, required mechanical ventilation for $>72$ hours; renal failure, newly required temporary or

TABLE 4. Univariate analysis of risk factors for SCI

\begin{tabular}{|c|c|c|c|c|c|c|}
\hline \multirow[b]{2}{*}{ Variable } & \multicolumn{3}{|c|}{ OR } & \multicolumn{3}{|c|}{ EVR } \\
\hline & $\begin{array}{l}\text { Odds } \\
\text { ratio }\end{array}$ & $95 \%$ CI & $\begin{array}{c}P \\
\text { value }\end{array}$ & $\begin{array}{l}\text { Odds } \\
\text { ratio }\end{array}$ & $95 \% \mathrm{CI}$ & $\begin{array}{c}P \\
\text { value }\end{array}$ \\
\hline Male sex & 1.39 & $0.89-2.18$ & .135 & 2.48 & $0.75-8.16$ & .116 \\
\hline Age $>65 y$ & 1.99 & $1.31-3.02$ & $<.001$ & 0.86 & $0.35-2.09$ & .746 \\
\hline Chronic lung disease & 1.55 & $1.00-2.41$ & .047 & 1.09 & $0.46-2.59$ & .829 \\
\hline Renal failure & 1.72 & $1.10-2.68$ & .016 & 3.01 & $1.37-6.61$ & .004 \\
\hline Coronary disease & 1.50 & $0.97-2.31$ & .063 & 0.86 & $0.30-2.50$ & .795 \\
\hline Aortic dissection & 0.87 & $0.60-1.26$ & .462 & 0.79 & $0.32-1.93$ & .610 \\
\hline Extended repair (Ex I/II) & 1.85 & $1.25-2.74$ & .002 & NA & NA & NA \\
\hline Emergency & 1.85 & $1.23-2.80$ & .003 & 2.14 & $0.98-4.65$ & .050 \\
\hline $\begin{array}{c}\text { Preoperative AKA } \\
\text { identification }\end{array}$ & 1.02 & $0.70-1.49$ & .887 & 1.33 & $0.64-2.76$ & .439 \\
\hline $\begin{array}{l}\text { Patent bilateral } \\
\text { hypogastric arteries }\end{array}$ & 0.34 & $0.17-0.67$ & .002 & 0.4 & $0.09-1.78$ & .222 \\
\hline
\end{tabular}

TABLE 5. Multivariate analysis of risk factors for SCI

\begin{tabular}{|c|c|c|c|c|c|c|}
\hline \multirow[b]{2}{*}{ Variable } & \multicolumn{3}{|c|}{ OR } & \multicolumn{3}{|c|}{ EVR } \\
\hline & $\begin{array}{l}\text { Odds } \\
\text { ratio }\end{array}$ & $95 \% \mathrm{CI}$ & $\begin{array}{c}P \\
\text { value }\end{array}$ & $\begin{array}{l}\text { Odds } \\
\text { ratio }\end{array}$ & $95 \%$ CI & $\begin{array}{c}P \\
\text { value }\end{array}$ \\
\hline Male sex & 1.84 & $0.98-3.42$ & .054 & 3.18 & $0.72-13.96$ & .124 \\
\hline Age $>65 y$ & 2.28 & $1.27-4.07$ & .005 & 0.70 & $0.24-2.00$ & .512 \\
\hline Chronic lung disease & 1.39 & $0.80-2.41$ & .235 & 1.15 & $0.45-2.95$ & .761 \\
\hline Renal failure & 1.15 & $0.59-2.23$ & 678 & 2.60 & $1.01-6.71$ & .048 \\
\hline Extended repair (Ex I/II) & 3.19 & $1.82-5.59$ & $<.001$ & NA & NA & NA \\
\hline Emergency & 2.08 & $1.00-4.29$ & .047 & 3.26 & $1.19-8.93$ & .021 \\
\hline $\begin{array}{l}\text { Preoperative examination } \\
\text { for AKA identification }\end{array}$ & 1.34 & $0.77-2.31$ & .299 & 1.81 & $0.73-4.45$ & .195 \\
\hline $\begin{array}{l}\text { Patent bilateral } \\
\text { hypogastric arteries }\end{array}$ & 0.35 & $0.16-0.79$ & .012 & 0.36 & $0.074-1.82$ & .220 \\
\hline
\end{tabular}

permanent dialysis; cardiac failure, required inotrope support for $>7$ days; gastroenteric, gastroenteric bleeding or bowel ischemia; bleeding, required transfusion amount $>5000 \mathrm{~mL}$ or chest reentry.

\section{DISCUSSION}

The Polish pathologist Adamkiewicz demonstrated the arterial vascular system of the spinal cord and the major radicular artery (today known as the AKA) in the 19th century, ${ }^{2}$ and most of his observations have been fully confirmed by our current knowledge of the system. Preoperative radiographic investigations of the AKA in aortic surgery, including arteriography, magnetic resonance arteriography, and CT arteriography, have been reported, ${ }^{6,7,9}$ elucidating the spinal cord circulation system. Subsequently, preoperative anatomic consideration has been well advanced; however, the importance of the arteries responsible for spinal cord protection in aortic surgeries remains unclear. Only a few studies have

TABLE 6. Demographic data of the patients undergoing OR for the aortic segment involving the AKA

\begin{tabular}{lc}
\hline \multicolumn{1}{c}{ Variable } & OR $(\mathbf{n}=\mathbf{4 5 4})$ \\
\hline Age $>65$ y & $254(55.9)$ \\
Male sex & $329(72.5)$ \\
Coronary artery disease & $254(55.9)$ \\
Renal failure & $65(14.3)$ \\
Chronic lung disease & $92(20.1)$ \\
Aortic dissection & $238(52.4)$ \\
Emergency repairs & $25(16.8)$ \\
Patent bilateral hypogastric arteries & $404(89.0)$ \\
AKA & \\
Reconstructed or preserved & $349(76.9)$ \\
Closed without reconstruction & $51(11.2)$ \\
Occluded & $54(11.9)$ \\
\hline OR, Open repair; $A K A$, Adamkiewicz artery.
\end{tabular}

$O R$, Open repair; $A K A$, Adamkiewicz artery. 


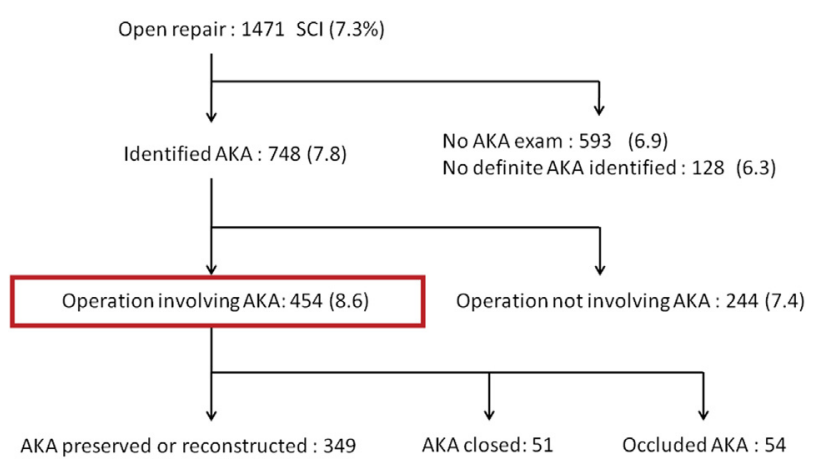

FIGURE 2. Subgroups of patients undergoing OR. Second row: identified AKA or not. Third row: operation involving the identified AKA or not. Bottom row: intraoperatively reconstructed or preserved patent AKA, closed patent AKA, or occluded AKA. SCI, Spinal cord injury; AKA, Adamkiewicz artery.

reported the positive efficacy of preoperative identification of the AKA. ${ }^{10,11}$ In Japan, numerous centers initiated AKA identification between 2000 and 2010, and have used this information for aortic surgery for descending or thoracoabdominal aortic diseases and reported its effect on surgical outcomes; however, the number of affected patients in each center was too small to clarify the impact of preoperative AKA identification. Thus, in the present study, we investigated the impact of preoperative examination of AKA identification on the prevention of SCI in ORs and EVRs through the multicenter registry of JASPAR, the first multicenter trial in this area.

In terms of AKA detection, the AKA was identified in $87.6 \%$ of cases overall, in the range of T8-T12 in $89.7 \%$ of cases and on the left side in $78.2 \%$ of cases. The AKA was not clearly identified in $10.0 \%$ of cases. The distribution of the AKA location and laterality were similar to those reported in previous studies. ${ }^{12-14}$

Hospital mortality of our cohort was acceptable in patients undergoing OR or EVR in emergency settings, compared with previous reports. ${ }^{3-5,10,11}$ The demonstrated

TABLE 7. Multivariate analysis of risk factors for SCI in OR for the aortic segment involving the AKA

\begin{tabular}{lccc}
\hline \multicolumn{1}{c}{ Variable } & Odds ratio & $\mathbf{9 5} \% \mathbf{C I}$ & $\boldsymbol{P}$ value \\
\hline Male sex & 2.18 & $0.85-5.61$ & .103 \\
Age $>65 \mathrm{y}$ & 2.81 & $1.27-6.41$ & $\mathbf{. 0 1 5}$ \\
Chronic lung disease & 1.06 & $0.47-2.39$ & .896 \\
Renal failure & 1.44 & $0.57-3.68$ & .444 \\
Extended repair (Ex I/II) & 1.94 & $0.91-4.14$ & .086 \\
Emergency & 1.91 & $0.47-7.68$ & .363 \\
Closure of identified AKA & 2.79 & $1.14-6.79$ & $\mathbf{. 0 2 4}$ \\
$\quad$ without reconstruction & & & \\
\hline Significant $P$ values (<.05) are in bold type. $C I$, Confidence interval; $A K A$, Adamkie- \\
wicz artery.
\end{tabular}

TABLE 8. Postoperative complications

\begin{tabular}{lcc}
\hline \multicolumn{1}{c}{ Variables } & OR $(\mathbf{n}=\mathbf{1 4 7 1})$ & EVR $(\mathbf{n}=\mathbf{9 6 4})$ \\
\hline Transient neurologic deficit, n (\%) & $40(2.7)$ & $16(1.6)$ \\
Permanent neurologic deficit, n (\%) & $66(4.5)$ & $30(3.1)$ \\
Prolonged ventilation, n (\%) & $352(23.9)$ & $79(8.2)$ \\
Renal failure, n (\%) & $128(8.7)$ & $44(4.6)$ \\
Cardiac failure, n (\%) & $60(4.1)$ & $13(1.3)$ \\
Gastroenteric disorder, n (\%) & $97(6.6)$ & $37(3.8)$ \\
Bleeding, n (\%) & $375(25.5)$ & $28(2.9)$ \\
Wound infection, n (\%) & $92(6.3)$ & $27(2.8)$ \\
\hline
\end{tabular}

$O R$, Open repair; $E V R$, endovascular repair.

risk factors for hospital mortality were advanced age ( $>65$ years), renal failure, and emergency surgery, also in agreement with the literature.

Risk factors for SCI identified in the multivariate analysis were advanced age ( $>65$ years), extended repair (Ex I/II), emergency repair, and occlusion of the bilateral hypogastric arteries in the OR group and renal failure and emergency repair in the EVR group. There was no significant difference in the incidence of SCI between the patients with and those without preoperative AKA identification in either treatment group, however. Essentially, the causes of SCI are multifactorial, including reduced systemic or distal aortic perfusion, less reconstruction of the intercostal arteries, embolism of the intercostal arteries responsible for spinal cord circulation, edema of the spinal cord, and others. Without good control of these factors, the anatomic approach to spinal cord blood circulation by AKA identification might not have a significant impact on spinal cord protection; however, further investigation of the subgroup of patients with an identified AKA and undergoing OR for the aortic segment involving the AKA, no reconstruction of the identified AKA and older age ( $>65$ years) were significant risk factors for SCI. According to the theory of an abundant collateral network of the spinal cord circulation, atherosclerosis in the elderly, extensive repair with thoracotomy, and sacrifice of numerous intercostal and/ or lumbar arteries might decrease the collateral circulation to the anterior spinal artery; the spinal cord would be vulnerable in these settings. ${ }^{15}$ Consequently, in such high-risk patients, preoperative AKA identification and its secure reconstruction might have a positive impact on spinal cord protection in OR beyond that in EVR. In both treatment groups, emergency repair was an independent risk factor for SCI. Outcomes generally were significantly worse In the emergency setting, with higher mortality and morbidity rates compared with elective cases for various reasons, including poor preoperative condition (eg, shock) and the need for a quick procedure with somewhat rough technique. However, from the standpoint of preoperative assessment of patient condition, there is also insufficient time for preoperative 
examinations. It can be argued that the multivariate analysis identifying emergency repair as a risk factor for SCI in both the OR and EVR groups might suggest a substantial risk of SCI in such emergency settings without preoperative AKA identification.

Anatomically, normally there are 3 routes of blood supply to the anterior spinal artery: the vertebral arteries, the hypogastric arteries, and the AKA (the radicular arteries from the intercostal arteries). In the patients who underwent OR, occlusion of the hypogastric arteries was a significant risk factor for SCI in the multivariate analysis. If at least 2 of the 3 systems were closed during aortic surgery, including EVR, then spinal cord circulation would be imperiled. In such a circumstance, preoperative anatomic evaluation of the AKA and its secure reconstruction would be more important to prevent SCI.

On the other hand, in the EVR group, the incidence of SCI was only $2.9 \%$, similar to previously reported figures. ${ }^{16,17}$ There was no significant difference in SCI incidence between patients with and those without preoperative AKA identification. In the subgroup of patients with an identified AKA, there also was no difference in the incidence of SCI between those with and those without the AKA covered by an endovascular prosthesis. The incidence of SCI in patients undergoing EVR is generally lower than that in patients undergoing $\mathrm{OR}^{16,17}$; however, Matsuda and coworkers ${ }^{17}$ reported that coverage of the long segments of the descending aorta was associated with a higher incidence of SCI. In this study, $90 \%$ of EVR cases had coverage of only the descending aorta, a major reason for the lower incidence of SCI. Moreover, in EVR, intraoperative hemodynamic stability is an advantage for maintaining spinal cord circulation, even if critical intercostal arteries are covered by endovascular prostheses without revascularization. However, with the advent of new endovascular devices, more extensive and complicated EVR procedures, which likely will carry high risks of SCI, will emerge in the future. In these circumstances, AKA identification will be of greater importance for prevention of SCI even in EVR.

In this multicenter study, no standardized procedural protocols were applied. In the majority of ORs, mild hypothermia in conjunction with the distal perfusion of partial CPB was applied. For the other cases, deep hypothermia with total CPB was also applied for brain and spinal cord protection. Excellent results were reported for descending and thoracoabdominal repairs with deep hypothermia ${ }^{18,19}$; however, deep hypothermia may cause coagulopathy and critical respiratory failure, including resultant pulmonary bleeding, and thus has not been widely applied. There was only a small number of cases of this type of surgery with deep hypothermia in this study. Although our analysis detected no advantage of the use of deep hypothermia for spinal cord protection, theoretically deep hypothermia provides intraoperative spinal cord protection during the disturbance of spinal cord circulation and prevention of reperfusion injury. ${ }^{20}$ Even in the extensive repairs of Ex I or II aortic pathologies, with identification and reconstruction of the AKA, deep hypothermia would provide better results by providing intraoperative ischemic tolerance and postoperative optimized circulation of the spinal cord.

On the other hand, selective perfusion of the intercostal arteries has been applied. ${ }^{21}$ This would be a good strategy for maintaining circulation of the spinal cord during aortic repairs. Theoretically, spinal cord protection against ischemia during the period of pressure reduction of the anterior spinal artery, including maintenance of the pressure of spinal cord circulation, quick control of back-bleeding, spinal fluid drainage, hypothermia, distal aortic perfusion, and reestablishment of blood flow to the radicular arteries after aortic repair to maintain circulation of the anterior spinal artery, with previously identified (not blind) AKA reconstruction, are important principles to promote spinal cord protection during aortic repair.

This multicenter study has some limitations. As described above, the repair methods and adjuncts for spinal cord protection were diverse among the centers, and at least 14 surgeons were involved in the OR and EVR cases. Preoperative identification of the AKA is obviously nothing more than one of the various strategies available to prevent SCI in OR and EVR. Further studies dealing with more detailed data, including patient characteristics, aortic pathologies, surgical strategies, procedures, and other techniques for spinal cord protection, such as cerebrospinal fluid drainage, neurologic monitoring, pharmacologic adjuncts, and perioperative management of hemodynamics, are needed to precisely demonstrate the impact of preoperative AKA identification.

Finally, this is the first study to examine the impact of preoperative AKA identification on spinal cord safety in descending/thoracoabdominal aortic repair dealing with a larger number of patients in a multicenter registry. In addition, the hospital mortality rate was almost the same as that reported from the annual registry of the Japanese Association for Thoracic Surgery, ${ }^{22}$ whose figures show that the contemporary standards in Japan are delivered by inexperienced hands.

\section{CONCLUSIONS}

In descending and thoracoabdominal aortic repairs, particularly in OR for aortic segments involving the origin of the AKA, preoperative AKA identification and its subsequent reconstruction or preservation are effective adjuncts 
for more secure protection of the spinal cord, along with other adequate management strategies for spinal cord protection.

\section{Conflict of Interest Statement}

Authors have nothing to disclose with regard to commercial support.

The authors are grateful to Akiko Kada and Kanae Takahashi, Center of Clinical Research, National Cerebral and Cardiovascular Center, for assistance with the statistical analysis of the data.

\section{References}

1. Safi HJ, Miller CC III, Huynh TT, Estrera AL, Porat EE, Winnerkvist AN, et al. Distal aortic perfusion and cerebrospinal fluid drainage for thoracoabdominal and descending thoracic aortic repair: ten years of organ protection. Ann Surg. 2003;238:372-80.

2. Adamkiewicz AA. Die blutgefässe des menschlichen rückenmarkes, II: die gefässe der rückenmarksoberfläche. Sitzungsberichte der Kaiserlichen Akademie der Wissenschaften. Mathematisch-Naturwissenschaftliche Classe. 1882;85: 101-30.

3. Griepp RB, Griepp EB. Spinal cord perfusion and protection during descending thoracic and thoracoabdominal aortic surgery: the collateral network concept. Ann Thorac Surg. 2007;83:S865-9.

4. Coselli JS, Bozinovski J, LeMaire SA. Open surgical repair of 2286 thoracoabdominal aortic aneurysms. Ann Thorac Surg. 2007;83:S862-4.

5. Schepens MA, Heijmen RH, Ranschaert W, Sonker U, Morshuis WJ. Thoracoabdominal aortic aneurysm repair: results of conventional open surgery. Eur J Vasc Endovasc Surg. 2009;37:640-5.

6. Yamada N, Okita Y, Minatoya K, Tagusari O, Ando M, Takamiya M, et al. Preoperative demonstration of the Adamkiewicz artery by magnetic resonance angiography in patients with descending or thoracoabdominal aortic aneurysms. Eur J Cardiothorac Surg. 2000;18:104-11.

7. Yoshioka K, Tanaka R, Kamada T, Abiko A. Three-dimensional demonstration of the collateral circulation to the artery of Adamkiewicz via the thoracodorsal artery with multi-slice computed tomography angiography. Eur J Cardiothorac Surg. 2010;37:1234.

8. Safi HJ, Winnerkvist A, Miller CC III, Iliopoulos DC, Reardon MJ, Espada R, et al. Effect of extended cross-clamp time during thoracoabdominal aortic aneurysm repair. Ann Thorac Surg. 1998;66:1204-9.

9. Heinemann MK, Brassel F, Herzog T, Dresler C, Becker H, Borst HG. The role of spinal angiography in operations on the thoracic aorta: myth or reality? Ann Thorac Surg. 1998;65:346-51.
10. Kawaharada N, Morishita K, Fukada J, Yamada A, Muraki S, Hyodoh H, et al. Thoracoabdominal or descending aortic aneurysm repair after preoperative demonstration of the Adamkiewicz artery by magnetic resonance angiography. Eur J Cardiothorac Surg. 2002;21:970-4.

11. Ogino H, Sasaki H, Minatoya K, Matsuda H, Yamada N, Kitamura S. Combined use of Adamkiewicz artery demonstration and motor-evoked potentials in descending and thoracoabdominal repair. Ann Thorac Surg. 2006;82:592-6.

12. Koshino T, Murakami G, Morishita K, Mawatari T, Abe T. Does the Adamkiewicz artery originate from the larger segmental arteries? J Thorac Cardiovasc Surg. 1999;117:898-905.

13. Wadouh F, Lindemann EM, Arndt CF, Hetzer R, Borst HG. The arteria radicularis magna anterior as a decisive factor influencing spinal cord damage during aortic occlusion. J Thorac Cardiovasc Surg. 1984;88:1-10.

14. Dommisse GF. The blood supply of the spinal cord: a critical vascular zone in spinal surgery. J Bone Joint Surg Br. 1974;56:225-35.

15. Etz CD, Halstead JC, Spielvogel D, Shahani R, Lazala R, Homann TM, et al. Thoracic and thoracoabdominal aneurysm repair: is reimplantation of spinal cord arteries a waste of time? Ann Thorac Surg. 2006;82: 1670-7.

16. Lee WA, Daniels MJ, Beaver TM, Klodell CT, Raghinaru DE, Hess PJ Jr. Late outcomes of a single-center experience of 400 consecutive thoracic endovascular aortic repairs. Circulation. 2011;123:2938-45.

17. Matsuda H, Ogino H, Fukuda T, Sasaki H, Minatoya K, Yagihara T, et al. Multidisciplinary approach to prevent spinal cord ischemia after thoracic endovascular aneurysm repair for distal descending aorta. Ann Thorac Surg. 2010;90: $561-5$.

18. Kouchoukos NT, Kulik A, Castner CF. Outcomes after thoracoabdominal aortic aneurysm repair using hypothermic circulatory arrest. J Thorac Cardiovasc Surg. 2013;145(3 Suppl):S139-41.

19. Fehrenbacher JW, Siderys H, Terry C, Kuhn J, Corvera JS. Early and late results of descending thoracic and thoracoabdominal aortic aneurysm open repair with deep hypothermia and circulatory arrest. J Thorac Cardiovasc Surg. 2010;140(6 Suppl):S154-60.

20. Faden AI, Simon RP. A potential role for excitotoxins in the pathophysiology of spinal cord injury. Ann Neurol. 1988;23:623-6.

21. Kawaharada N, Ito T, Koyanagi T, Harada R, Hyodoh H, Kurimoto Y, et al. Spinal cord protection with selective spinal perfusion during descending thoracic and thoracoabdominal aortic surgery. Interact Cardiovasc Thorac Surg. 2010;10: 986-90.

22. Sakata R, Fujii Y, Kuwano H. Thoracic and cardiovascular surgery in Japan during 2008: annual report by the Japanese Association for Thoracic Surgery. Gen Thorac Cardiovasc Surg. 2010;58:356-83.

Key Words: aorta, spinal cord protection, Adamkiewicz artery 